\title{
Preliminary report: Outbreak of Legionnaires' disease in a hotel in Calp, Spain, update on 22 February 2012
}

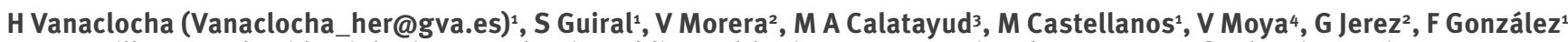

1. Surveillance and Epidemiologic Control Unit, Public Health Directorate, Regional Goverment of Valencia, Spain

2. Epidemiology Unit, Public Health Center, Dènia, Spain

3. Epidemiology Unit, Public Health Center, Benidorm, Spain

4. Environmental Health Unit, Public Health Directorate, Regional Goverment of Valencia, Spain

Citation style for this article:

Vanaclocha H, Guiral S, Morera V, Calatayud MA, Castellanos M, Moya V, Jerez G, González F. Preliminary report: Outbreak of Legionnaires' disease in a hotel in

Calp, Spain, update on 22 February 2012

Euro Surveill. 2012;17(8):pii=20093. Available online: http://www.eurosurveillance.org/ViewArticle.aspx?Articleld=20093

Article published on 23 February 2012

Research is ongoing on eighteen cases of Legionellosis, including four deaths, identified among tourists and employees in a hotel in Calp, Spain. Cases occurred during a period of two months, indicating the possibility of a point-source transmission at the hotel. An environmental investigation identified several positive samples in the hotel, which as a precautionary measure, was closed until requested improvements were made. Surveillance measures currently remain active.

\section{Outbreak description and} epidemiological investigation

On 14 December 2011 a Spanish tourist, who had stayed at a hotel in Calp, on the east coast of Spain, between 27 and 29 November was confirmed as a case of Legionella pneumonia. Thirteen days later, on 27 December 2011, a Spanish employee at the same hotel was identified as a second case. This prompted an epidemiological investigation to confirm or rule out an outbreak.

On 11 January 2012 another case was reported via the European Legionnaires' Disease Surveillance Network (ELDSNet) and involved an English tourist who had also stayed at the hotel. Following this, on 17 January 2012, three additional cases related to the hotel were reported, all British citizens.

The European case definition [1] was adapted for this outbreak, and a confirmed case was defined as a patient with clinical diagnosis of pneumonia, who had stayed or worked at the hotel between two and ten days before the onset of symptoms, with laboratory findings indicative of Legionella infection, including a positive urine test for Legionella pneumophila antigen, or a positive culture or isolation from respiratory secretions.

Currently, the outbreak is restricted to 18 cases. All cases were confirmed by positive urine antigen. Seven samples are pending sequencing by the Genomics and
Health Joint Unit, Centro Superior de Investigación en Salud Pública (CSISP) -University of Valencia, Spain. There have been four deaths, all involving male travelrelated cases, over 70 years of age. Two of the cases who died had not sought prior medical care, while the other two cases died in the hospital 12 and 39 days after onset of symptoms.

All cases had stayed or worked at the same hotel in Calp during the incubation period of their illness. There were a total of 11 men and seven women with a mean age of 70 years (range: 44-88 years). Partial information is available on predisposing factors of cases: smoking in $3 / 9$, heart disease in $2 / 13$ and chronic respiratory disease in $1 / 13$.

Fifteen of the eighteen cases were travel-associated (one Spanish, twelve English and two French) and three were members of the hotel staff. The three cases who were part of the hotel staff had an average age of 58 years (range: 47-74 years). For all of the 18 cases but two, symptoms began between 4 December 2011 and 2 February 2012. The date of onset of symptoms is unknown for two of the four cases who died (Figure).

Travel-associated cases occupied different rooms in the hotel, except for three couples, who respectively shared a room. Only two cases used the hotel's spa facilities.

\section{Environmental investigation}

When the first case appeared, on 4 December, the registered documentation on the Facilities Management Program Risk of the hotel was reviewed. We verified that certificates of cleaning and disinfection of water deposits, as well as of the network of cold water for human consumption and hot water were compliant with the Spanish Legionella surveillance legislation [2]. The documents certifying compliance were dated from 31 January 2011. 
When the second case of Legionnaires' disease, a hotel employee, was reported, a new on-site investigation was immediately launched. In addition to the previously inspected documents, we obtained the analytical results, dated from 29 November 2011, of routine water samples from the hot-water deposits, jacuzzi, cold-water tank and rooms. All of the seven water samples that had been analysed had been negative for Legionella.

On 11 January, via ELDSNet a third, travel-associated case was reported. As a result, a thorough inspection of the hotel premises was performed. Chlorine levels and temperatures were checked in each column of the drinking water pipes. Deficiencies in the hot-water temperature and other structural points were detected, as hot water stagnated in the feedback circuit. Twelve new water samples that were taken, yielded negative results a few days later. Nevertheless, all the hotel facilities were cleaned by hyperchlorination [2]. Two days later, additional water and biofilm samples were collected to check the efficiency of the cleaning procedures. All the samples tested negative.

On 31 January, new water and biofilm samples were taken from the network of cold water for human consumption and the hot water. Fourteen biofilm samples tested positive and the hotel was immediately closed on 2 February.

\section{FIGURE}

Cases of Legionnaires' disease, by date of symptom onset, ongoing outbreak in Calp, Spain, 24 November 2011-22 February $2012(\mathrm{n}=18)$

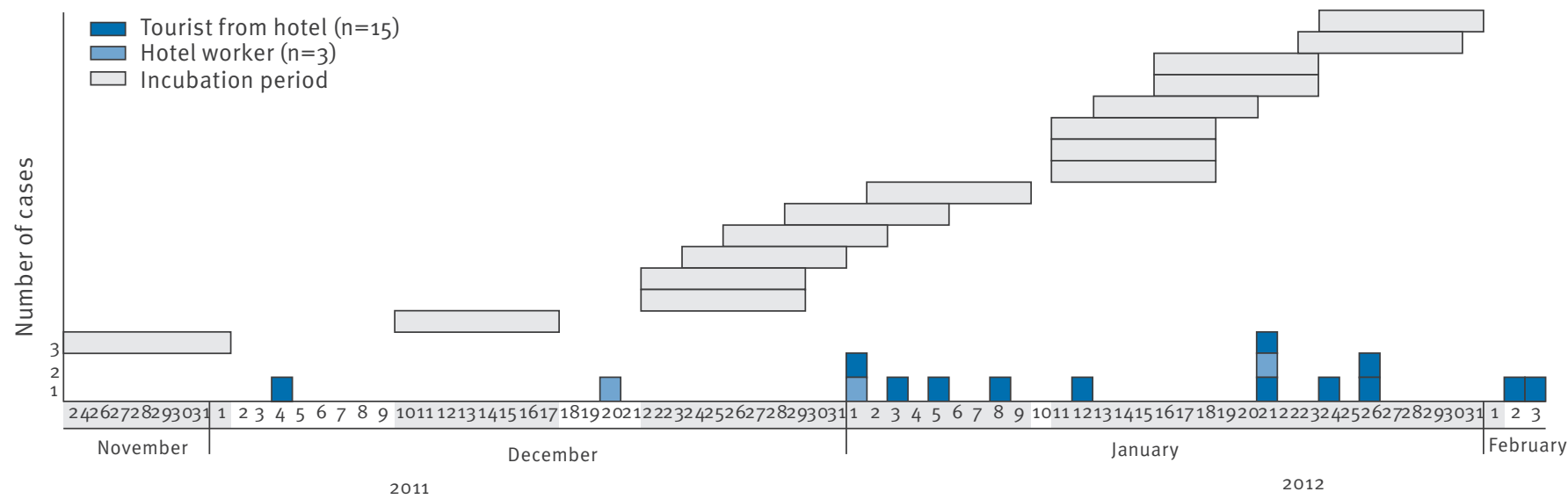

Date of onset

Dates of symptom onset for two of 18 cases who died are not known. These two cases are not shown on the figure.

TABLE

Environmental investigation, outbreak of Legionnaires' disease in Calp, Spain, 24 November 2011-22 February 2012

\begin{tabular}{|c|c|c|}
\hline Date of action & Action & Result \\
\hline 04 December 2011 & $\begin{array}{l}\text { Review of the registered documentation on the Facilities } \\
\text { Management Program Risk of the hotel }\end{array}$ & $\begin{array}{l}\text { Certificates, dating from } 31 \text { January } 2011 \text {, of cleaning and } \\
\text { disinfection of water deposits, the network of cold water for } \\
\text { human consumption and hot water were obtained }\end{array}$ \\
\hline 03 January 2012 & On-site inspection & $\begin{array}{l}\text { A whirlpool cleaning and disinfection certificate dated from } \\
02 \text { November } 2011 \text { was obtained } \\
\text { The certificate dating from } 29 \text { November } 2011 \text { showed that } \\
\text { analytical results of seven routine water samples had been } \\
\text { negative for Legionella }\end{array}$ \\
\hline 12 January 2012 & $\begin{array}{l}\text { On-site investigation } \\
\text { Water chlorine levels and temperatures were checked } \\
\text { Seven new water samples were taken }\end{array}$ & All water samples were negatives \\
\hline 16-17 January 2012 & All the hotel facilities were cleaned by hyperchlorination & $\begin{array}{l}\text { One water and } 12 \text { biofilm samples were taken on } 19 \text { January } \\
2012 \text { to check the result of the cleaning procedure }\end{array}$ \\
\hline 19 January 2012 & $\begin{array}{l}\text { New on-site investigation } \\
\text { One water and } 12 \text { biofilm samples were taken }\end{array}$ & $\begin{array}{l}\text { Deficiencies in the hot-water temperature and other } \\
\text { structural points } \\
\text { All the samples tested negative }\end{array}$ \\
\hline 31 January 2012 & 32 water and 24 biofilm samples were taken & 14 biofilm samples were positive on 2 February 2012 \\
\hline 2 February 2012 & 14 biofilm samples were positive & Precautionary closure of the hotel \\
\hline $8-9$ February 2012 & $\begin{array}{l}\text { Cleaning and hyperchloration after correction of } \\
\text { deficiencies in the water distribution network was } \\
\text { conducted between } 8 \text { and } 9 \text { February }\end{array}$ & The hotel reopens to the public on 10 February \\
\hline
\end{tabular}


Environmental intervention

\section{requested from the hotel}

As a result of the environmental investigations, the hotel had to make changes in the hot water system to prevent the growth of Legionella. The changes had to ensure that the hot water temperature would be higher than $50^{\circ} \mathrm{C}$ in all endpoints. Improvements in the water disinfection system were also requested and the use of well-water for irrigation and toilets' cisterns was prohibited.

\section{Discussion}

From 1999 to 2009, 26\% of Legionnaires' disease outbreaks in Spain have been travel-associated, and have affected 435 people [3]. However, in recent years there has been a decrease in the number of cases and outbreaks affecting travellers [4,5]. Interestingly, travel-associated Legionnaires' disease mortality in non-Spanish citizens is 2.6 times higher than in Spanish citizens travelling in their own country [3].

Here we report on the ongoing investigations into an outbreak in a single hotel in Calp, affecting 18 individuals and causing four fatalities. In the last 10 years, the incidence of travel-associated Legionella clusters in Calp has been very low. In 2006, an outbreak in the same hotel involved six cases. During 2011, a cluster of two travel-associated cases was reported in a different hotel of the same city.

Unlike other point-source transmission outbreaks, the onset of the one reported here was insidious with 13 days between the notifications of the two first cases. In addition, the second case was a hotel worker. These circumstances have made the early stages of the investigation quite difficult [6-8].

In this outbreak, the majority of hotel guests were from the European Union (EU), especially from the United Kingdom, France, Italy and Belgium. There were also Spanish guests and some from other countries outside the EU (United States, Russia, Kazakhstan, Brazil, New Zealand, Australia). Identified cases were from three EU countries. For the surveillance of Legionnaires' disease and especially for the detection of travel-associated clusters, collaboration among European countries through ELDSNet is very important and facilitates a rapid risk assessment [9-11]. Nevertheless, it would be interesting to have more detailed information about the patients involved in travel-associated clusters to improve research and control of outbreaks.

Guests and tour operators have been informed about the outbreak and strict control and cleaning measures, including the closure of the hotel, were implemented. The hotel resumed normal operation once the structural deficiencies and additional cleaning procedures were performed. Surveillance measures will remain active until further notice.
The results of genomics analyses of human and environmental samples are still awaited. The final report on the outbreak will be delivered once it is considered closed and we have all the results related to the investigation.

\section{References}

1. European Commission Decision 2008/426/EC of 28 April 2008 amending Decision 2002/253/EC laying down case definitions for reporting communicable diseases to the Community network under Decision No 2119/98/EC of the European Parliament and of the Council (notified under document number C(2008) 1589) (Text with EEA relevance). Available from: http://eur-lex.europa.eu/Result.do? $\mathrm{T}_{1}=\mathrm{V}_{4} \& \mathrm{~T}_{2}=2008 \& \mathrm{~T}_{3}=$ 426\&RechType $=$ RECH_naturel\&Submit=Search

2. Real Decreto $865 / 2003$, de 4 de Julio, por el que se establecen los criterios higiénico-sanitarios para la prevención y control de la legionelosis [Royal Decree 865/2003 of 4 July, establishing the hygienic criteria for the prevention and control of legionellosis]. Spanish.

3. Brotes de legionelosis notificados a la Red Nacional de Vigilancia Epidemiológica. Años 1999 a 2009. Centro Nacional de Epidemiología. Instituto de Salud Carlos III. Noviembre de 2010 [Outbreaks of legionellosis reported to the National Epidemiological Surveillance Network. 1999 to 2009. National Epidemiology Center. Instituto de Salud Carlos III. November 2010]. Spanish. Available from: http://www.isciii.es/ISCIII/ es/contenidos/fd-servicios-cientifico-tecnicos/fd-vigilanciasalertas/fd-enfermedades/Legionelosis_informe_brotes_ RENAVE.pdf

4. Joseph CA, Ricketts KD, Yadav R, Patel S, on behalf of the European Working Group for Legionella Infections. Travelassociated Legionnaires' disease in Europe in 2009. Euro Surveill. 2010;15(41):pii=19683. Available from: http://www. eurosurveillance.org/ViewArticle.aspx?Articleld=19683

5. European Centre for Disease Prevention and Control (ECDC). Legionnaires' disease in Europe 2009. Stockholm: ECDC; Sep 2011. Available from: http://ecdc.europa.eu/en/publications/ Publications/1109_SR_Legionnaires\%2odisease_ Europe_2009.pdf

6. Rota MC, Scaturro M, Fontana S, Foroni M, Boschetto G, Trentin L, et al. Cluster of travel-associated Legionnaires' disease in Lazise, Italy, July to August 2011. Euro Surveill. 2011;16(40): pii=19982. Available from: http://www. eurosurveillance.org/ViewArticle.aspx?Articleld=19982

7. Payne L, Andersson Y, Blystad H, Nguyen Tran Minh N, Ruutu P, Joseph C, et al. Outbreak of legionnaires' disease among tourists staying at a hotel in Phuket, Thailand. Euro Surveill. 2007;12(2):pii=3109. Available from: http://www. eurosurveillance.org/ViewArticle.aspx?Articleld=3109

8. Joseph C. Outbreak of legionnaires' disease associated with visits to Belgium. Euro Surveill. 2002;6(40):pii=1889. Available from: http://www.eurosurveillance.org/ViewArticle. aspx?Articleld $=1889$

9. Rota MC, Cano Portero R, Che D, Caporali MR, Hernando V, Campese C. Clusters of travel-associated Legionnaires' disease in Italy, Spain and France, July 2002 - June 2006. Euro Surveill. 2007;12(11): pii=744. Available from: http://www. eurosurveillance.org/ViewArticle.aspx?Articleld=744

10. Joseph C. Managing Legionnaires' disease in Europe: the need for international collaboration. Euro Surveill. 2007;12(11):pii=743. Available from: http://www. eurosurveillance.org/ViewArticle.aspx?Articleld=743

11. Joseph C. Launch of new European guidelines for control and prevention of travel associated legionnaires' disease. Euro Surveill. 2002;6(27):pii=1926. Available from: http://www. eurosurveillance.org/ViewArticle.aspx?Articleld=1926 